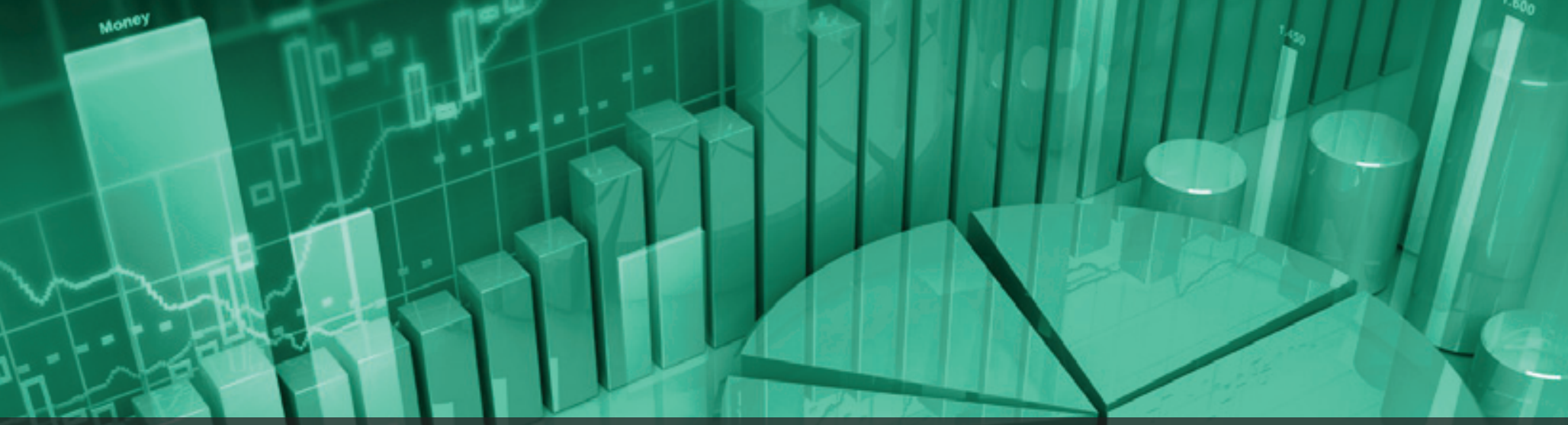

\title{
The Destruction of a Safe Haven Asset?
}

\section{By Dirk G. Baur \& Kristoffer J. Glover}

Dirk G. Baur is Associate Professor in Finance at the University of Technology Sydney, Australia.

Kristoffer J. Glover is a Postdoctoral Research Fellow in Finance at the University of Technology Sydney, Australia.

Gold has been a store of value for centuries and a safe haven for investors in the past decades. However, the increased investment in gold for speculative or hedging purposes has changed the safe haven property. We demonstrate theoretically and empirically that investor behaviour has the potential to destroy the safe haven property of gold. The results suggest that an asset cannot be both an investment asset and an effective safe haven asset. This finding has important implications for financial stability since assets are more likely to exhibit excess comovement and volatility in the absence of a safe haven.

Keywords: safe haven; gold; investor behaviour; funding constraints; contagion

\section{Introduction}

Gold has various roles in the global economy. It is said to be an inflation hedge, a "store of value", and a safe haven. The safe haven means that the asset provides shelter in times of financial turmoil. For example, if negative news hit stocks in a specific country, leading to extreme losses and contagion to other stock markets, a safe haven is supposed to be immune to such an event and not lose its value. More recently, it appears that gold has been subject to increased investment demands evidenced by the extreme price increase from around US\$300 to above US $\$ 1,900$ within a period of 10 years. This price increase is comparable to the bubble in Japanese stocks in the 1980s and the "dotcom" bubble in Nasdaq in the 1990s.

At first blush, it seems that gold has many appealing properties, but can one asset really be all things to all men? We illustrate that it cannot. Firstly, we show empirically that gold has often not displayed the properties of a store of value or an inflation hedge in the past 40 years. Secondly, using financial theory and a simple thought experiment, we demonstrate that the use of a safe haven asset as an

investment or speculative asset weakens the safe haven property or, in extreme cases, destroys it. An empirical analysis fully supports the predictions of the thought experiment. ${ }^{1}$

There is a growing literature on gold and safe haven assets (e.g. see Baur and Lucey, 2010; Baur and McDermott, 2010; and Ranaldo and Söderlind, 2010). To the best of our knowledge this is the first paper that analyzes the dynamic role of gold as a safe haven asset and the possibility that specific actions of investors undermine the safe haven property. This paper also forms part of a broader research question "Does the belief in gold as a safe haven asset reinforce or weaken its safe haven properties?"

The remainder of this paper contains three sections, a theoretical section, an empirical section and a policy section which addresses the implications for financial stability. The final part consists of a summary of the main results and concluding remarks. 


\section{How investors can destroy the safe haven property of gold}

The equity market downturn in 2000 and the low historical correlation of commodities with stocks prompted many investors to view commodities as a desirable alternative asset class. Since this time, commodities markets (including gold) have seen the investment of billions of dollars from institutional investors such as pension funds, insurance companies, and hedge funds. Consequently, commodities now constitute a considerable proportion of many investors' portfolios (see Tang and Xiong, 2010). As a result of this, the price of a commodity such as gold is no longer determined simply by its supply and demand. The trading of investors who hold both stocks and gold in their portfolios can act as a channel to induce linkages between stock and gold prices. The exact nature of these links depends on investors' trading strategies.

The main thesis of this paper is that the increased holdings of gold by many investors in recent years have the potential to undermine and possibly destroy the safe haven property of gold. To illustrate our point we describe the following simple thought experiment. Consider two scenarios labelled A and B. In scenario A investors hold stocks and bonds but do not hold significant amounts of gold in their portfolios. In scenario $B$ investors hold stocks, bonds and gold. Scenario A can also be characterized as a period in which gold appears to be segmented from other asset classes and in which gold has not been discovered by the average investor ("the crowd"), i.e. investors have not realized the gains from diversification if commodities in general, or gold in particular, are added to a portfolio. Consequently, scenario $B$ can be described as a period in which gold is more integrated and the potential gains from diversification are exploited. ${ }^{2}$

In a next step, we assume that there is a shock that negatively affects the prospects and thus the valuations of firms leading to large losses in the (global) stock market. We further assume that investors face borrowing or funding constraints (e.g. see Boyer, Kumagei and Yuan; Brunnermeier and Pedersen, 2009). However, the main findings also hold without this assumption.

In scenario $A$, investors react to the negative news by selling some of their holdings in stocks. The first movers manage to minimise their losses by moving out of stocks early (pushing stock prices down) and are left with excess capital to invest elsewhere. The "second" movers will incur a potentially large loss on their stock positions. Furthermore, they may even be forced to liquidate some of their positions due to margin constraints. Since investors in scenario A do not hold gold in their portfolios prior to the shock they cannot sell gold to meet margin calls or to reduce the risk of their portfolio after the shock. In this scenario gold is not affected by the shock and will act as a safe haven and not decrease in value. Baur and McDermott (2010) distinguish between a weak safe haven effect in which the price of gold does not decrease and a strong safe haven effect in which the price of gold increases. Scenario $A$ is consistent with a weak safe haven effect. If we further assume that some investors use some of the capital freed by the sale of stocks to invest in gold-since it is perceived as a safe haven-scenario A would display a strong safe haven effect. In this scenario we hence observe that investors' perceptions about gold as a safe haven, and their subsequent actions, have the effect of reinforcing the safe haven property of gold. Hence their beliefs are self-fulfilling.

In scenario B, however, the story can be quite different. Investors may show a similar initial reaction to the negative news as in scenario A, i.e. they sell some of their holdings in stocks and possibly buy gold. However, in contrast to scenario A, investors do hold gold in their portfolios, allowing for additional mechanisms through which the shock in the stock market can subsequently influence the market for gold. These mechanisms are related to investors' portfolio optimization demands, liquidity constraints, and possible behavioural biases.

We identify four possible mechanisms through which an increase in the number of investors holding both gold and stocks in their portfolios in scenario B could undermine the safe haven property of gold. The ideas presented here are closely linked to the literature on financial contagion, where contagion can also be transmitted through many different channels. However, we mention here only those mechanisms that could have the potential to destroy the safe haven property of gold.

Firstly, and perhaps most importantly, the cross-market re-balancing effect (see Kodres and Pritsker, 2002) asserts that investors respond to shocks in the stock market by readjusting their portfolios and re-evaluating their demand for other assets, including gold. ${ }^{3}$ Assuming that an investor's optimal asset allocation is to maintain a constant proportion of their wealth invested in each asset, they will attempt to readjust their portfolios to regain their optimal portfolio weight. ${ }^{4}$ In the process of portfolio re-balancing, over-weighted assets are sold and under-weighted assets are purchased, predicting a reduced demand for gold, and downward pressure on gold prices. ${ }^{5}$ We note that there will exist a natural time lag between the shock in the stock market and the resulting effect on the gold market since the time until investors' portfolios moved sufficiently 
out of line to warrant (costly) re-balancing would be strictly positive. However, as more investors hold gold, this time could be expected to shorten.

A second, related, mechanism is the wealth effect (see Kyle and Xiong, 2001), which states that when investors lose money in one asset, their capacity to bear risk is reduced, resulting in the liquidation of positions in all risky assets, hence reducing pricing in all markets.

Thirdly, the liquidity shock effect (cf. Brunnermeier and Pedersen, 2009) could also be at work, in which market participants who need to liquidate a portion of their assets to obtain cash, perhaps due to a call for additional collateral, would choose to liquidate assets in a number of different markets, effectively transmitting the liquidity shock between markets.

Finally, a more behavioural effect, the disposition effect (see Tversky and Kahneman, 1974), suggests that investors are reluctant to sell assets which incur losses (they do not want to realize losses), instead choosing to sell assets that have not decreased in value. Since, in scenario $B$, gold is not under immediate selling pressure (and is expected to be so due to the safe haven property) investors may choose to liquidate gold instead. This option is not available to investors in scenario A.

All the mechanisms described above would place downward pressure on gold prices in response to a negative shock in the stock market. The implication being that the more people holding gold in their portfolios prior to a shock in the stock market, the more likely mechanisms such as those described above would negatively influence the price of gold and weaken the effectiveness of the safe haven, i.e. shorten the period in which it does not lose its value.

This thought experiment provides testable implications: (i) gold is an effective safe haven in periods following no significant investment demand for gold and (ii) gold is not an effective safe haven in periods following significant investment demand for gold. We use consistent price changes over a certain period as indication of significant changes in investment demand.

\section{Empirical Evidence}

Figure 1 shows the evolution of the price of gold and the MSCl stock index both measured at a daily frequency and denominated in US dollars from January 1970 to August 2012.6

The figure illustrates that the price of gold increased significantly from around US $\$ 300$ to above US $\$ 1,900$ between 2000 and 2011 . This price increase is consistent with significant investment demand for gold and shows typical features of a bubble. ${ }^{7}$

Figure 1: Performance of stock market and safe haven asset.

The graph shows the evolution of the MSCI World stock market index in US dollars (dashed black line) and the price of gold in US dollars (solid line) from 1970 to 2012.

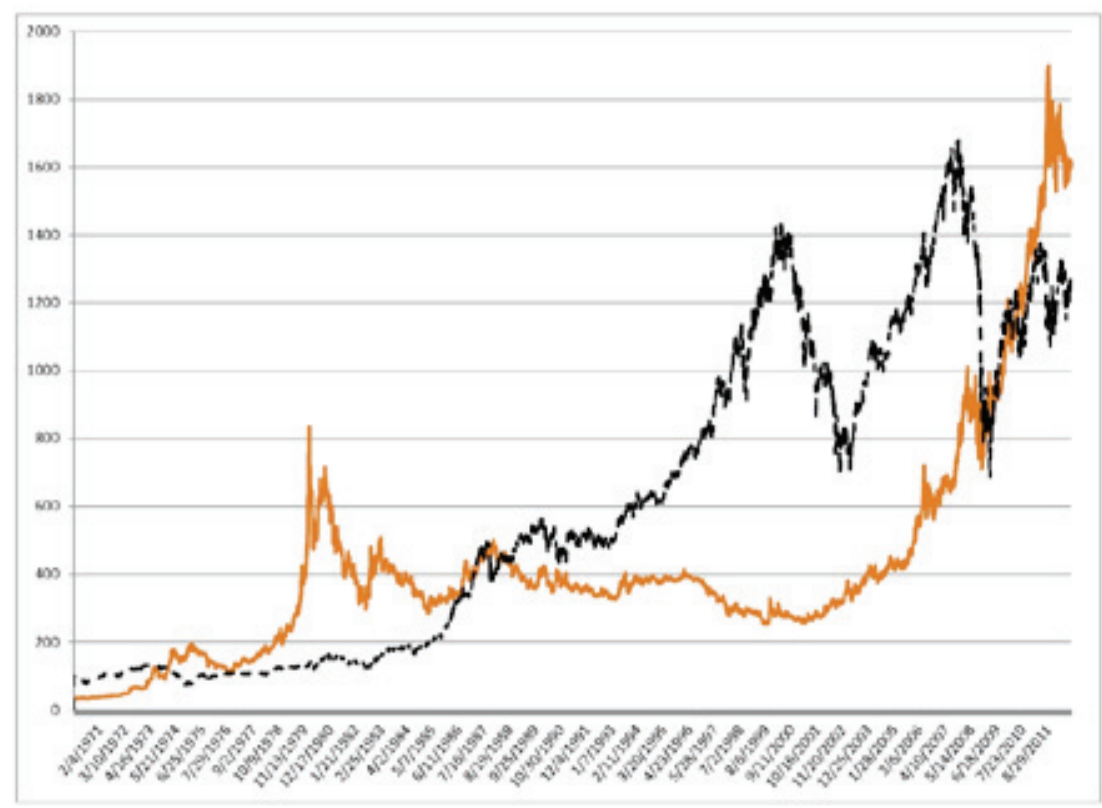




\section{Figure 2: Graphical analysis of crash / financial crises.}

The graph shows the crashes of October 1987 (left), September 11, 2001 (centre), and the subprime crisis and Lehman bankruptcy 2008 (right).
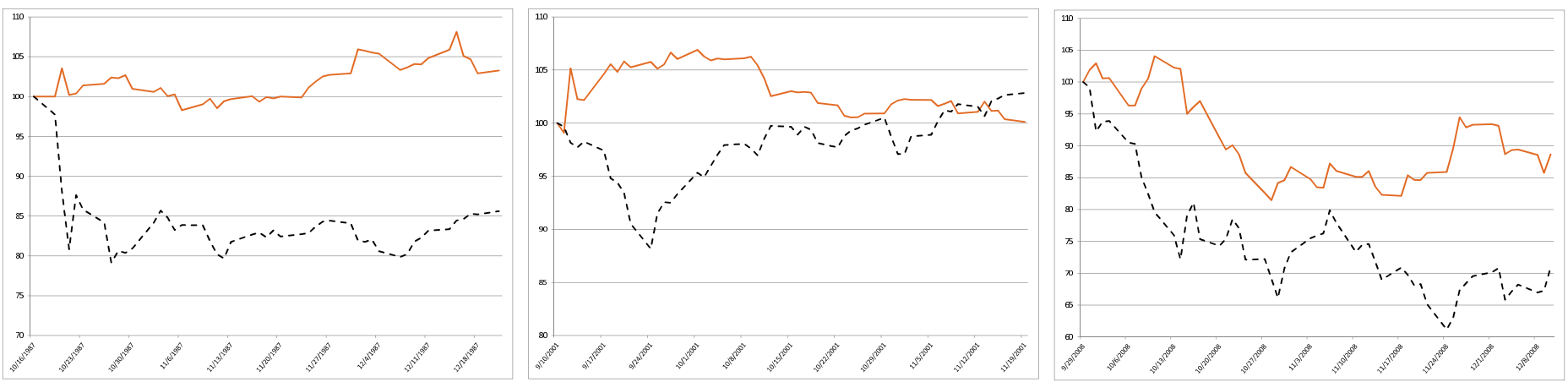

The graph also shows that gold was in a 20-year bear market between the late 1970s and 2000. This excludes gold from being a "store of value" in a strict sense since the price fell for a relatively long period. Because the price of gold did not hold its value for a significant period with positive inflation rates, gold was also not an effective inflation hedge. 8

Figure 2 illustrates the price effects of stocks and gold during specific crises periods and stock market crashes. The plots display the 1987 stock market crash, the September 11, 2001 terrorist attacks and subsequent fall in stock prices, and the subprime crisis and Lehman bankruptcy in 2008.9

The graphs show the evolution of the price of gold and a global stock market index around the crisis outbreak and demonstrate that gold acted as a safe haven in all periods. However, the crisis in 2008 is significantly different, a positive increase in the price of gold consistent with a strong safe haven effect is followed by a drop in the price of gold to a level below 100 within 4 days compared to around 15 trading days in the other periods. ${ }^{10}$ This price drop is consistent with scenario B. The price drop followed a sustained period of increased investment demand. ${ }^{11}$ The fact that the price did not fall jointly with the stock market is also consistent with our theory outlined in scenario $B$, since most of the mechanisms described predict a lagged response of gold price movements to the drop in stock prices. For example, margin calls or portfolio rebalancing, both requiring a sale of gold, would only arise after some time into the crisis.

There is another important difference in the 1987 and 2001 crashes compared to the crisis in 2008. Gold showed an inverse relationship with global stocks in the first two episodes but a rather synchronized behaviour shortly after the start of the stock market downturn in 2008. This is further evidence that the effectiveness of the safe haven asset has weakened.

It must also be mentioned that the safe haven effect was generally short-lived, i.e. the price of gold does not fall for a relatively short period of time (around 15 trading days) but tends to fall after that (see Baur and Lucey, 2010). If investors buy gold in response to a negative news shock in the stock market the price of gold increases (strong safe haven effect). If stock prices continue to fall several days after the initial news arrival investors may find themselves in a situation similar to scenario $B$ as described above, since investors would now be holding a significant proportion of gold. In this regard, it could be argued that this effect was always present and that the destruction of the safe haven effect is nothing new. What is new is that the period of 15 trading days is reduced significantly and in some conditions fully eliminated, i.e. reduced to zero trading days.

The finding of a short-lived safe haven effect is also directly linked to the empirical rejection of the store of value hypothesis. If the safe haven effect of gold was a persistent, long-lived, effect, gold would never exhibit a price drop and thus be a store of value.

Finally, an analogy based on the definition of a haven as a "port" and "shelter from the storm" may provide a simpler and perhaps more intuitive illustration of the mechanisms described in this paper. In such an analogy, the increased holding of gold in many investors' portfolios has resulted in most investors now having two boats in operation; one out at sea and susceptible to a financial storm and a second in the port. During times of financial turmoil, the investors 
(boats) who arrive at the port first are able to seek shelter from the storm and the continued arrival of investors to the port enhance their security further, due to the safety in numbers. However, as the storm begins to ease, those investors with boats still remaining at sea, and now damaged from the storm, must send out their second boat from the port to the aid of the first.

\section{Financial Stability Implications}

The existence or non-existence of a safe haven effect has strong implications for financial stability. In scenario A investors do not hold significant fractions of gold in their portfolios and thus cannot sell gold in response to their losses in the stock market. As a consequence gold will not lose its value at a time when global stock markets are in turmoil thereby positively influencing investor sentiment and indirectly stabilizing markets.

In scenario $B$, investors have incentives (due to portfolio re-balancing or wealth effects) or requirements (due to liquidity constraints) to sell gold following a negative shock in the stock market. This may lead to reduced selling pressure in the stock market. However, this is rather a shortterm effect. When investors realize that the value of the safe haven asset falls (due to the sale of gold) it is likely that this will lead to increased uncertainty and instability. For example, they may overreact to the falling price in the gold market by selling more stocks or gold potentially increasing volatility in both markets.

The scenarios described in this paper also suggest that there is an impossibility of an effective use of a safe haven asset. ${ }^{12}$ If investors do not hold the safe haven asset before the occurrence of a crash or a crisis (scenario A), the price will be stable but investors do not have the ability to reduce holdings in the safe haven asset to offset their losses in the stock market. In other words, they cannot fully exploit the safe haven property. If, on the other hand, investors do hold the safe haven asset before the occurrence of a crash or a crisis (scenario B), its price is more likely to fall following a downturn in the stock market. Hence, investors destroy the safe haven property precisely because they want to use it. Furthermore, if investors realize that the safe haven property is significantly influenced by their portfolio compositions, and thus their behaviour, this may change their belief in the effectiveness of the safe haven property and therefore fully eliminate it.

\section{Conclusions}

We used a simple thought experiment to demonstrate theoretically that significant investment in gold - due to its perceived safe haven and hedging properties - can reduce the effectiveness and thus duration of the safe haven effect. The empirical analysis further showed that the duration of the safe haven effect during the subprime crisis in 2008 was indeed reduced significantly. If investors become aware of the mechanisms working against the safe haven and change their beliefs about its effectiveness the safe haven property could be destroyed all together. Finally, we argued that the destruction of a safe haven asset has strong implications for financial stability. It is likely that crashes and crises are more extreme in the absence of a safe haven asset. 


\section{Appendix: Optimal Portfolio Weights}

Consider an investor faced with the problem of finding the trading strategy $\pi_{t}$ that maximizes their expected utility of terminal wealth

$$
\max _{\pi} \mathrm{E}_{w}\left[U\left(W_{T}^{\pi}\right)\right]
$$

where $\mathrm{W}$ denotes their wealth process (started at $w$ ), and T their time horizon. Merton $(1969,1971)$ provided a simple and elegant solution to this problem (in continuous time) in a world where assets follow log-normal distributions (the Black-Scholes-Merton world) and for investors that have a power utility functions (of the CRRA class) given by $U(x)=x^{1-\gamma} /(1-\gamma)$, where $\gamma>0$ is the risk aversion coefficient. The optimal portfolio weights in this case are found to be

$$
\boldsymbol{\pi}_{t}=\frac{1}{\gamma} \Sigma_{t}^{-1}\left(\mu_{t}-r_{f} \mathbf{1}\right)
$$

where $\Sigma_{t}$ denotes the covariance matrix, $\mu_{t}$ denotes the vector of expected returns, $r_{f}$ the risk-free rate, and 1 the vector of ones. In the case of constant expectations for $\Sigma$ and $\mu$, this solution indicates that investors should strive to maintain a constant fraction of their wealth invested in each risky asset.
For illustrative purposes, we consider the two risky asset case in which we have

$$
\begin{gathered}
d S_{t} / S_{t}=\mu_{S} d t+\sigma_{S} d B_{t}^{S} \\
d G_{t} / G_{t}=\mu_{G} d t+\sigma_{G} d B_{t}^{G}
\end{gathered}
$$

with $\operatorname{Cov}\left(d B_{t}^{S}, d B_{t}^{G}\right)=\rho d t$ where $S_{t}$ and $G_{t}$ denote the prices of stocks and gold, respectively, and $\rho$ the correlation between stocks and gold. Given this, we see from (1), that the portfolio fractions for stock and gold are constant in time and given by

$$
\begin{array}{r}
\pi^{S}=\frac{\mu_{S}-r_{f}-\rho \frac{\sigma_{S}}{\sigma_{G}}\left(\mu_{G}-r_{f}\right)}{\gamma \sigma_{S}^{2}\left(1-\rho^{2}\right)} \\
\pi^{G}=\frac{\mu_{G}-r_{f}-\rho \frac{\sigma_{G}}{\sigma_{S}}\left(\mu_{S}-r_{f}\right)}{\gamma \sigma_{G}^{2}\left(1-\rho^{2}\right)}
\end{array}
$$

What is neglected from the above is the existence of transaction costs. In the presence of such costs the optimal strategy is modified such that there is a no-trade region around the Merton proportions (given above) where a trade is made to rebalance the portfolio when the portfolio weights get too far out of line (see Davis and Norman, 1990). Such a strategy is consistent with the way in which many institutional investors operate and supports the existence of a lagged response between a shock in the stock market and (optimal) portfolio re-balancing. 


\section{Acknowledgements}

We thank Thomas McDermott and Niels Schulze for detailed comments and suggestions based on an earlier version of this paper.

\section{References}

Baur, D. G. and Lucey, B. M. (2010). Is Gold a Hedge or a Safe Haven? An Analysis of Stocks, Bonds and Gold. Financial Review 45, 217-229.

Baur, D. G. and McDermott, T. K. (2010). Is Gold a Safe Haven? International Evidence. Journal of Banking \& Finance 34, 1886-1898.

Boyer, B. H., Kumagai, T. and \& Yuan, K. (2006). How Do Crises Spread? Evidence from Accessible and Inaccessible Stock Indices. Journal of Finance 61, 957-1003.

Brunnermeier, M. K., and Pedersen, L. H. (2009). Market Liquidity and Funding Liquidity. Review of Financial Studies $22,2201-2238$.

Davis, M. H. A. and Norman, A. R. (1990). Portfolio Selection with Transaction Costs. Mathematics of Operations Research 15, 676-713.

Grossman, S. J. and Stiglitz, J. E. (1980). On the Impossibility of Informationally Efficient Markets. American Economic Review 70, 393-408.

Kodres, L. E. and Pritsker, M. (2002). A Rational Expectations Model of Financial Contagion. Journal of Finance 57, 769-799.

Kyle, A. S. and Xiong, W. (2001). Contagion as a Wealth Effect. Journal of Finance 56, 1401-1440.

Merton, R. (1969). Lifetime Portfolio Selection under Uncertainty: The Continuous-time Case. Review of Economics and Statistics 51, 247-257.

Merton, R. (1971). Optimum Consumption and Portfolio Rules in a Continuous-time Model. Journal of Economic Theory 3, 373-413.

Phillips, P. C. B. and Yu., J. (2011). Dating the Timeline of Financial Bubbles During the Subprime Crisis. Quantitative Economics 2, 455-491.

Ranaldo, A. and Söderlind, P. (2010). Safe Haven Currencies. Review of Finance 14, 385-407.

Tversky, A. and Kahneman, D. (1974). Judgment under Uncertainty: Heuristics and Biases. Science 185, 1124-1131.
Tang, K. and Xiong, W. (2010). Index Investment and Financialization of Commodities. NBER Working Paper Series, WP16385.

World Gold Council (2011). Gold Demand Trends Second Quarter 2011 . www.gold.org, August 20. 
1 In this paper we focus on gold, however our theoretical arguments would work for any safe haven asset subject to increased investment or speculative demand.

2 Note that the safe haven property is not equal to a hedge or (mean-variance) diversification property (see Baur and Lucey, 2010).

3 Note that for non-US investors the role of the US dollar would have an additional effect on the portfolio rebalancing demands since gold is denominated in US dollars. When the US dollar appreciates, gold becomes more expensive to international investors and their demand would decrease, causing gold prices to co-move with the US dollar exchange rate. We do not explore this effect further as the ideas in this paper can be expressed without this additional effect.

4 Appendix A provides details of the assumptions required to ensure that the optimal portfolio allocation for an investor is to maintain a constant proportion of his/her wealth in each asset. These assumptions may not apply to all investors but the idea that one should maintain a constant proportion of wealth in each asset class has permeated modern portfolio theory and is the aim of many institutional money managers.

5 For example, if the value of stocks and gold in US dollars is given by Ws $=\$ 400$ and $W_{G}=\$ 400$ with the remaining capital in the risk-free asset, $W_{R}=\$ 200$; corresponding to a portfolio composition of $(40 \%, 40 \%, 20 \%)$. A significant loss in the value of stocks to $\mathrm{Ws}_{\mathrm{s}}=\$ 300$ would result in the portfolio composition moving out of line with its initial optimum, motivating a re-balancing of the portfolio by transferring $\$ 40$ from gold and $\$ 20$ from the risk-free asset to obtain $W_{S}=\$ 360, W_{G}=\$ 360$, and $W_{R}=\$ 180$.

6 On August 15, 1971 President Nixon decreed that the US would no longer exchange dollars for gold, effectively ending the gold standard. Figure 1 shows the stability of the price from January 1970 until August 1971 and the increased fluctuation of the price of gold following the announcement in August 1971.

7 The World Gold Council provides investment demand figures. For example, in 2001 the investment demand (excluding jewellery and industrial demand) was 350 tonnes of gold with a value of 3.1 bn US dollar. In 2008, investment demand was 1,200 tonnes of gold valued at 33.5bn US dollars (World Gold Council, 2011). This extreme trend can be explained with the financialization of commodities in general, the invention and popularity of exchange-traded funds, and the repercussions of the subprime crisis in 2008.

8 One may argue that gold is not meant to be a hedge against actual inflation but a hedge against (future) expected inflation. This argument could be used in light of the sovereign debt crisis and investors' expectations that paper currency may depreciate significantly boosting the price of gold. However, this argument does not work for the pre-2008 period.

9 Since a definition of the subprime crisis and the Lehman bankruptcy period is not straightforward and arbitrary to some degree we tried alternative start dates to analyse the robustness of the results, observing similar findings for all dates. The use of the MSCI World index complicates the optimal choice of the crisis date since some countryspecific effects are less evident in a global context. Crisis time-lines, as published by central banks for example, can identify key dates of crisis origination and thus help to define and justify the crisis window. A focus on the US stock market would lead to stronger results.

10 See Baur and Lucey (2010) on the duration of the safe haven effect.

11 We tested whether gold displayed bubble-like features using a bubble test proposed by Phillips and Yu (2011). The results show that gold indeed followed a price path consistent with a bubble.

12 This idea is related to the impossibility of informationally efficient markets proposed by Grossman \& Stiglitz (1980).

\section{Corresponding Author}

Dirk G. Baur. UTS, Business School, Finance Discipline Group, PO Box 123 Broadway, Sydney, NSW 2007, Australia,

Email: dirk.baur@uts.edu.au. 